Article

\title{
Species surface concentrations on a SAPO-34 catalyst exposed to a gas mixture
}

\author{
Yasukazu Kobayashi, Yuxin Li, Yao Wang, Dezheng Wang * \\ Department of Chemical Engineering, Tsinghua University, Beijing 100084, China
}

\section{A R T I C L E I N F O}

Article history:

Received 26 October 2013

Accepted 23 December 2013

Published 20 March 2014

Keywords:

Ideal adsorbed solution theory (IAST)

Adsorption isotherm

Mixed gas adsorption

SAPO-34 catalyst

\begin{abstract}
A B S T R A C T
The use of the Langmuir isotherm for competitive adsorption and the use of ideal adsorbed solution theory (IAST) for calculating the surface concentrations of adsorbed species on a SAPO-34 catalyst exposed to a gas mixture were compared with experimental measurements. Two binary mixtures, namely, methanol and dimethyl ether (DME) at $80^{\circ} \mathrm{C}$ and DME and ethene at $25^{\circ} \mathrm{C}$ were used. IAST gave good agreement in the whole range of experimental concentrations, while Langmuir theory only gave good agreement up to when one-third of the acid sites were covered and then showed increasingly large deviations with increased pressure, and it failed to capture the phenomenon that the concentration of an adsorbed species with a smaller saturation adsorption capacity would decrease with increased pressure. Thus, for reactions of gas mixtures whose components have different saturation adsorption capacities, Langmuir theory can only be used for the reaction kinetics when the surface concentrations are quite low, and IAST should be used when the surface concentrations are high.
\end{abstract}

(C) 2014, Dalian Institute of Chemical Physics, Chinese Academy of Sciences. Published by Elsevier B.V. All rights reserved.

\section{Introduction}

The multicomponent Langmuir isotherm for competitive adsorption is traditionally used to calculate the surface concentrations $\left(C_{\mathrm{s},(i)}\right)$ on a surface that is in equilibrium with a gas mixture. However, the Langmuir isotherm is only consistent with thermodynamics when the monolayer capacity $\left(C_{\text {sat }}\right)$ are the same for all species, or when the coverages are small [1-3]. The surface concentration is the amount of adsorbed species per unit mass of catalyst, and its units are mmol/g in this work. The coverage is the occupied fraction of monolayer capacity, $C_{\mathrm{s},(i)} / C_{\mathrm{sat}}$. The failure of Langmuir theory has been verified by molecular simulation with ZSM-5 by Krishna and Baur [3], who explained that space constraint in the zeolite allowed a small molecule to occupy spaces that were too small for big species, which gave different adsorption capacity for the hexane iso- mers. They showed that the reaction kinetics were erroneous when the Langmuir isotherm was used for surface concentrations and that ideal adsorbed solution theory (IAST) should replace the Langmuir model. Their result depended on that ZSM-5 has intersecting channels where the branched isomer only adsorbed at the intersections and there were two adsorption sites that were such that branched $\mathrm{C}_{6} \mathrm{H}_{14}$ only adsorbed on one type of site while $n$ - $\mathrm{C}_{6} \mathrm{H}_{14}$ adsorbed on both types of sites and its adsorption on the second site was facilitated when it was also adsorbed on the first site. In this work, we showed that the replacement of one adsorbate by another also existed in a SAPO-34 zeolite without intersecting channels and although they were also two different adsorption sites, the different adsorbates adsorbed on both types of sites.

However, reaction kinetics computations using the IAST need a more complicated calculation, unlike computations us-

\footnotetext{
* Corresponding author. Tel: +86-10-62794467; Fax: +86-10-62772051; E-mail: wangdezheng@tsinghua.edu.cn This work was supported by the National Natural Science Foundation of China (21173125).

DOI: 10.1016/S1872-2067(14)60007-3 | http://www.sciencedirect.com/science/journal/18722067 | Chin. J. Catal., Vol. 35, No. 3, March 2014
} 
ing the Langmuir isotherm which are quite simple and it would also be useful to know the range where it can still be used. The IAST uses experimental adsorption isotherms, which can be just an experimental curve, to express the adsorbed phase concentration of each species in terms of its gas phase concentration. In the case of an adsorption system where the adsorption of all adsorbed species obey isotherms of the Langmuir class, which is true of adsorption in many zeolites [4], the IAST is an extension of Langmuir theory for competitive adsorption that further accounts for the relationship that must exist between the gas phase and surface mole fractions, for which the IAST uses Raoult's law. The word "solution" in IAST is used to denote the use of Raoult's law and not that the theory treats the adsorbed phase as a liquid with a surface tension determined by the pore size, that is, it is not akin to the Dubinin class of adsorption theories.

In this study, we examined the validity of the Langmuir isotherm for competitive adsorption for calculating surface concentrations with mixtures of some of the gases in the reaction system of the SAPO-34 catalyzed methanol-to-olefins (MTO) process. We discuss the range in which the Langmuir equation can be used. Because the Langmuir isotherm would give erroneous results of the surface concentrations of a gas mixture only when the mixture comprises molecules that have different adsorption capacity [1-3], from the gases of interest in the MTO process, we chose to work with the two binary mixtures of methanol and dimethyl ether (DME) and DME and ethene because these pairs have differences in adsorption capacity. Ideally, methanol should be chosen for the second pair with ethene, but unfortunately ethene has a small adsorption constant and it needed high pressures to give it significant coverages, and it was difficult to use methanol at these pressures in isotherm measurements because of its low vapor pressure at room temperature.

\section{Experimental}

\subsection{SAPO-34 synthesis}

The sample was synthesized using a standard recipe derived from that in a Union Carbide patent of Lok et al. [5]. It gave XRD characterization that was in good agreement with the XRD patterns of the zeolites synthesized with triethylamine (TEA) as the template and known as "SAPO-34" in the literature $[5,6]$. More details of the catalyst were given by Li et al. [7]. Argon adsorption isotherms at $-186^{\circ} \mathrm{C}$ gave its surface area, pore volume, and pore size, calculated by the density functional theory method, as $1247 \mathrm{~m}^{2} / \mathrm{g}, 0.297 \mathrm{ml} / \mathrm{g}$, and $0.552 \mathrm{~nm}$, respectively. The particle size was 1 to $2 \mu \mathrm{m}$ in the scanning electron microscopy (SEM) images. The acid site density was calculated from SEM-energy dispersive spectroscopy (EDS) and $\mathrm{NH}_{3}$ temperature-programmed desorption (TPD) to be 1.0 $\mathrm{mmol} / \mathrm{g}$.

\subsection{Chemisorption experiments}

The adsorption experiments were performed in a volumet- ric manometry apparatus. More details of the apparatus were described in a previous report [8]. The sample cell was modified to have a thin capillary tube placed near the sample with the other end of the tube connected to a leak valve, which was used for getting gas samples into a mass spectrometer (MS). The adsorbate gases used were methanol, DME, and ethene, and binary mixtures of methanol-DME and DME-ethene with a methanol:DME molar ratio of 63:37 and a DME:ethene molar ratio of 57:43, respectively. The adsorption experiments were conducted after the sample was preheated at $400{ }^{\circ} \mathrm{C}$ for $5 \mathrm{~h}$ under vacuum, then first saturated by the binary gas mixture to cover the sites of irreversible adsorption and evacuated so that the subsequent measurement measured only the reversible adsorbed amounts because only these were used for the isotherms. The irreversibly adsorbed amounts in the adsorption of methanol and of DME have been reported in our previous paper [9]. No irreversible adsorption was observed in the ethene adsorption experiments here. The dead volume of the sample call was $40 \mathrm{ml}$, which was large enough to allow the composition of the gas phase to be sampled by the MS after equilibrium was reached for each dosage with negligible loss of gas from the sample cell. Equilibrium in the gas phase was verified before admitting the next dose by comparing MS samples taken at successive time intervals to confirm that there was no change in the gas phase. Equilibrium was usually established within 3 $\mathrm{h}$ after each dose. During the sampling, it was checked that the MS wide scan spectra gave no detectable peaks of other species to confirm that no reaction occurred in the adsorption experiments. The gas phase composition at equilibrium and the mass balance were used to calculate the experimental surface concentrations of each component in the mixed gas adsorption experiment.

A heat flow microcalorimeter was used to measure the calorimetric (heat of adsorption versus coverage) curves. The microcalorimeter was homemade based on the design by Handy et al. [10] but had the modification that flat thermopiles were used instead of their thimble-shaped thermopiles. This allowed sample powder particles to be distributed as a very thin layer of less than $1 \mathrm{~mm}$ thickness to get a quicker time response from gas adsorption on the sample. The thermopiles were purchased from International Thermal Instruments Corp. (Model BHT). The voltages from the thermopiles were amplified by amplifiers purchased from Nanjing University (Model ND-802). The output signals from the amplifiers were recorded by an analog-to-digital conversion board in a personal computer.

\subsection{Theories}

\subsubsection{Langmuir theory}

The Langmuir isotherm equations are routinely derived in textbooks on adsorption or chemical kinetics. Here, only non-dissociated adsorption occurred. The most commonly used model is the single site Langmuir (SSL) model, which is Eq. (1). However, with many microporous materials, esp. zeolites, it has been found that there are more than one type of sites, and several successful application of the dual site Langmuir (DSL) model have been reported [11-13]. In this work, Eq. (2), which 
uses Henry's law instead of the Langmuir isotherm for the second site, was used because with our experimental pressure range, only the linear part of the isotherm for the second site was measured, that is, it would require higher pressures than was possible with our apparatus to significantly populate the second site. For a multicomponent system where all the components can adsorb competitively on all the sites, the isotherm equations for the SSL and DSL models are, respectively, Eq. (3) and Eq. (4).

$$
\begin{gathered}
C_{\mathrm{s}}=C_{\mathrm{sat}} \frac{b P}{1+b P} \\
C_{\mathrm{s}}=C_{\mathrm{sat}} \frac{1}{1+b_{1} P}+K P \\
C_{\mathrm{s},(i)}=C_{\mathrm{sat}} \frac{b_{(i)} P_{(i)}}{1+\sum_{j=1}^{N} b_{(j)} P_{(j)}} \\
C_{\mathrm{s},(i)}=\frac{C_{\mathrm{sat},(i)} b_{(i)} P_{(i)}}{1+\sum_{j=1}^{N} b_{(j)} P_{(j)}}+K_{(i)} P_{(i)}
\end{gathered}
$$

where $C_{\mathrm{s},(i)}$ is surface concentration of adsorbed species $i, C_{\mathrm{sat},(i)}{ }^{1}$ is the saturation capacity of the $i^{\text {th }}$ species on Type 1 sites, $b_{(i)}$ is the adsorption equilibrium constant for adsorption of the $i^{\text {th }}$ species on Type 1 sites, $P_{(i)}$ is the partial pressure of the $i^{\text {th }}$ species, and $K_{(i)}$ is the Henry constant for the adsorption of the $i^{\text {th }}$ species on Type 2 sites. Eq. (4) was used for calculating the surface concentrations of a mixture after the various parameters were obtained from the pure component isotherms by curve fitting using Eq. (2). It has been shown [1-3] that the Langmuir isotherms for gas mixtures are compatible with thermodynamics only when the saturation capacity of each adsorbate on each of the different sites is the same for all adsorbates.

\subsubsection{Ideal adsorbed solution theory (IAST)}

The IAST by Myers and Prausnitz [14] was developed for calculating the surface concentrations (fractional coverages) in a multicomponent system where the saturation capacity of each adsorbate can be different for any of the different types of sites. The theory is based on that the multicomponent adsorbed phase behaves as an ideal solution, which has been shown to be a reasonable assumption for adsorption in many zeolites [15]. The equations of the IAST [14] are Eqs. (5) to (7):

$$
\begin{aligned}
& \int_{0}^{P_{(1)}^{0}} \frac{C_{(1)}}{P_{(1)}} \mathrm{d} P_{(1)}=\int_{0}^{P_{(2)}^{0}} \frac{C_{(2)}}{P_{(2)}} \mathrm{d} P_{(2)}=\cdots=\int_{0}^{P_{(N)}^{0}} \frac{C_{(N)}}{P_{(N)}} \mathrm{d} P_{(N)} \\
& P_{(i)}=x_{(i)} P_{(i)}^{0}(\pi) \quad \text { for } i=1,2, \cdots, N \\
& \frac{1}{C_{\text {tot }}}=\sum_{j=1}^{N} \frac{x_{(j)}}{\mathrm{C}_{(j)}^{0}}
\end{aligned}
$$

where $P_{(i)} 0(\pi)$ is the equilibrium "vapor pressure" of pure $i$ adsorbed at the same spreading pressure $\pi$, and $C_{(i)} 0$ is the adsorbed amount of $i$ species at $P_{(i)}{ }^{0}(\pi)$. These equations cannot be solved to give one equation for the surface concentrations in terms of the gas phase concentrations, and so the calculation requires a trial and error procedure such as that given in Do
[1]. In this work, they were solved for the adsorbed phase mole fractions using iteration by Newton's method with a Matlab computer program from Do [1]. The required input data are the adsorption isotherms of the individual adsorbates, or when an adsorption isotherm can be fitted by a Langmuir equation, the parameters in the Langmuir equation used.

\section{Results and discussion}

\subsection{Methanol-DME binary mixture}

The IAST gives the same surface concentrations as the Langmuir equations for multicomponent systems when the saturation adsorbed amounts are same for all component gases [2]. In order to experimentally verify whether IAST should be used instead of the Langmuir equations, the experiment should be performed with adsorbates that have different saturation capacity. Thus, the two pairs of methanol-DME and DME-ethene mixtures were chosen as the adsorbates on SAPO-34 for the gas mixture experiments. The adsorption isotherms and calorimetric curves for methanol adsorption and DME adsorption on the same SAPO-34 zeolite sample as was used here have been previously reported [9]. Methanol has a saturation capacity on the acid sites (Type 1) that is twice that of DME, being 2.12 and $1.04 \mathrm{mmol} / \mathrm{g}$, respectively. Both the adsorption isotherms, which were Langmuir isotherms, and the heats of adsorption showed that the acid sites do not differ much in strength. It was also shown that in addition to adsorption on acid sites, there was also adsorption on a weaker site, which was possibly physisorption on the neutral surface of the zeolite (Type 2 sites), which continued to be populated at high pressures. Thus the DSL equation was used to fit the isotherms, which gave good fits. Curve fitting using the SSL equation was also done for comparison, but the fits were not satisfactory, esp. at higher pressures. A good fit for the single component data is very important for accurate multicomponent calculations, that is, there can be large errors in the multicomponent calculations if an inaccurate single component isotherm was used [1]. For the correct determination of the saturation capacity on Type 1 sites of this system, simultaneous calorimetric curve measurements were necessary [9]. The optimized parameters for the DSL equation of Eq. (2) are given in Table 1.

The binary mixture experiment with methanol and DME was conducted using the same conditions as the pure component experiment. After each dose of the mixture of known gas composition, individual adsorbed amounts were calculated by sampling the change in the gas phase composition after equi-

\section{Table 1}

Component DSL parameters for the calculation of the surface concentrations of mixtures.

\begin{tabular}{lcccc}
\hline $\begin{array}{l}\text { Adsorbate } \\
\text { gas }\end{array}$ & \multirow{2}{*}{$t /{ }^{\circ} \mathrm{C}$} & \multicolumn{3}{c}{ DSL parameter } \\
\cline { 3 - 5 } & & $C_{\text {sat, }(i)} /(\mathrm{mmol} / \mathrm{g})$ & $b_{(i)} /\left(\mathrm{kPa}^{-1}\right)$ & $K_{(i)} /(\mathrm{mmol} /(\mathrm{g} \cdot \mathrm{kPa}))$ \\
\hline $\mathrm{CH}_{3} \mathrm{OH}$ & 80 & 2.12 & 0.50 & 0.0765 \\
$\mathrm{DME}$ & 80 & 1.04 & 0.38 & 0.0052 \\
$\mathrm{DME}$ & 25 & 1.47 & 1.11 & 0.0012 \\
$\mathrm{C}_{2} \mathrm{H}_{4}$ & 25 & 1.0 & 0.03 & 0.0028 \\
\hline
\end{tabular}


librium was established. Figure 1 shows the measured individual concentrations of methanol and DME, along with the calculated results from Langmuir theory and IAST using the pure component DSL parameters. The two theories calculated almost the same amounts of adsorbed methanol and DME at low pressures, where both theories gave good agreement with the data points. However, deviations in the calculations by Langmuir theory became larger in the higher pressure region while the IAST calculations still agreed with experimental data.

In the calculations using the Langmuir equation, deviations in the amount of adsorbed methanol and DME were observed for pressures above $2 \mathrm{kPa}$. These deviations were due to that DME was no longer being adsorbed, and then with further increase in pressure, some DME actually desorbed. The IAST results indicated that this was because methanol has a larger saturation capacity on the acid sites of the SAPO-34 catalyst than DME. Krishna and coworkers [3] have explained this adsorbate replacement as an entropy requirement, but we believe it is an enthalpy requirement, that is, more adsorbed molecules mean more heat of adsorption released. Regardless of the fundamental reason for why it occurred, it still can be concluded that IAST correctly captured the trend of first non-increasing and then decreasing amounts of adsorbed DME with increasing pressure, whereas the Langmuir equation forced the DME coverage to have a monotonic increase with pressure, that is, it failed to give any desorption and consequent decreased coverage, and the deviations from experimental data were larger
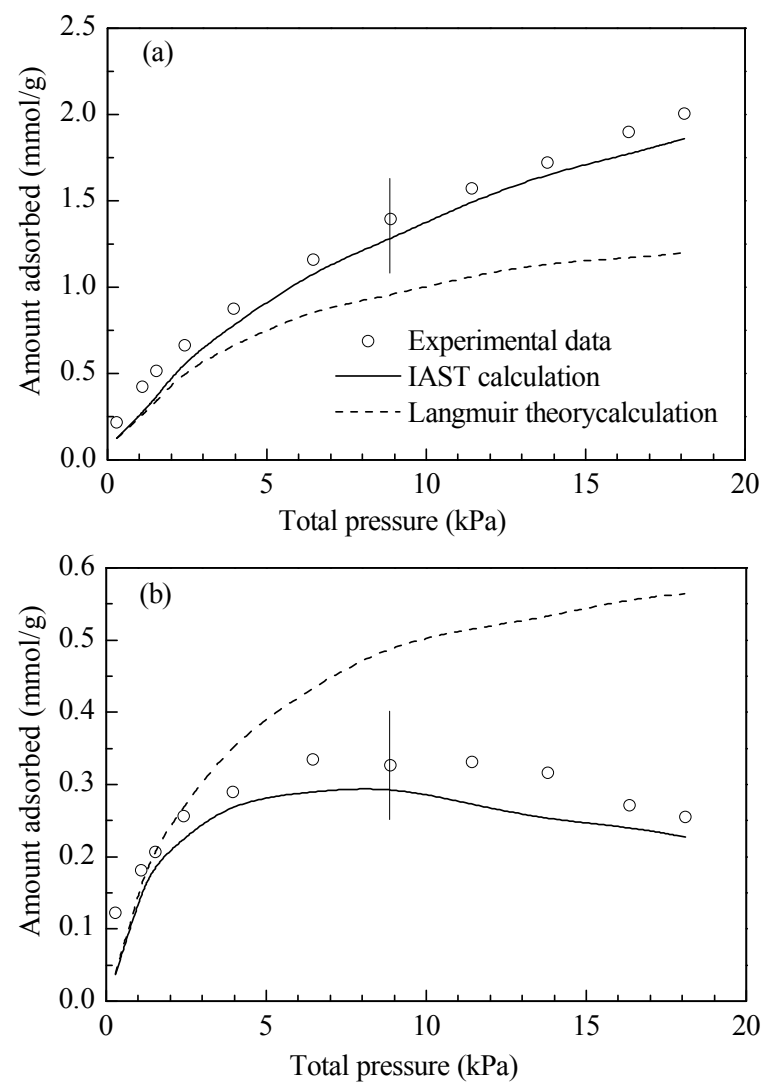

Fig. 1. Surface concentration of (a) methanol and (b) DME due to adsorption of the binary gas mixture. Vertical lines indicate saturation of Type 1 sites, shown by a sharp drop in the calorimetric curves. with increasing pressure. From this comparison between IAST and the multicomponent Langmuir equation, we concluded that IAST should be used to calculate species surface concentrations at moderate to high total coverages for adsorption situations where different adsorbates have different saturation adsorption capacity. However, because the calculations with the Langmuir isotherm equation were in good agreement up to about one-third of the saturation coverage of Type 1 sites, if this is the range of coverage existing in catalytic reactions, the Langmuir isotherm equation could be satisfactory for reaction kinetics calculations in this range.

Figure 2 shows the measured isotherm and calorimetric curve for the binary mixture. In a previous paper [9], it was discussed that it is important to measure a calorimetric curve in addition to the isotherm for a dual site surface because the calorimetric curve is needed to get the coverage at which the stronger Type 1 sites were saturated, which was shown by a sharp drop in the calorimetric curve when this coverage was exceeded. Here, too, the calorimetric curve of the binary mixture showed a sharp drop in the heat of adsorption, which was observed at $8.9 \mathrm{kPa}$ where the amounts adsorbed were 1.39 and $0.33 \mathrm{mmol} / \mathrm{g}$ for methanol and DME, respectively. Taking this as the pressure where saturation of Type 1 sites occurred, it can be seen that although at saturation, the mole fraction of DME on the surface was much less than that in the gas phase, it was still significant. That the DME coverage stayed nonzero up
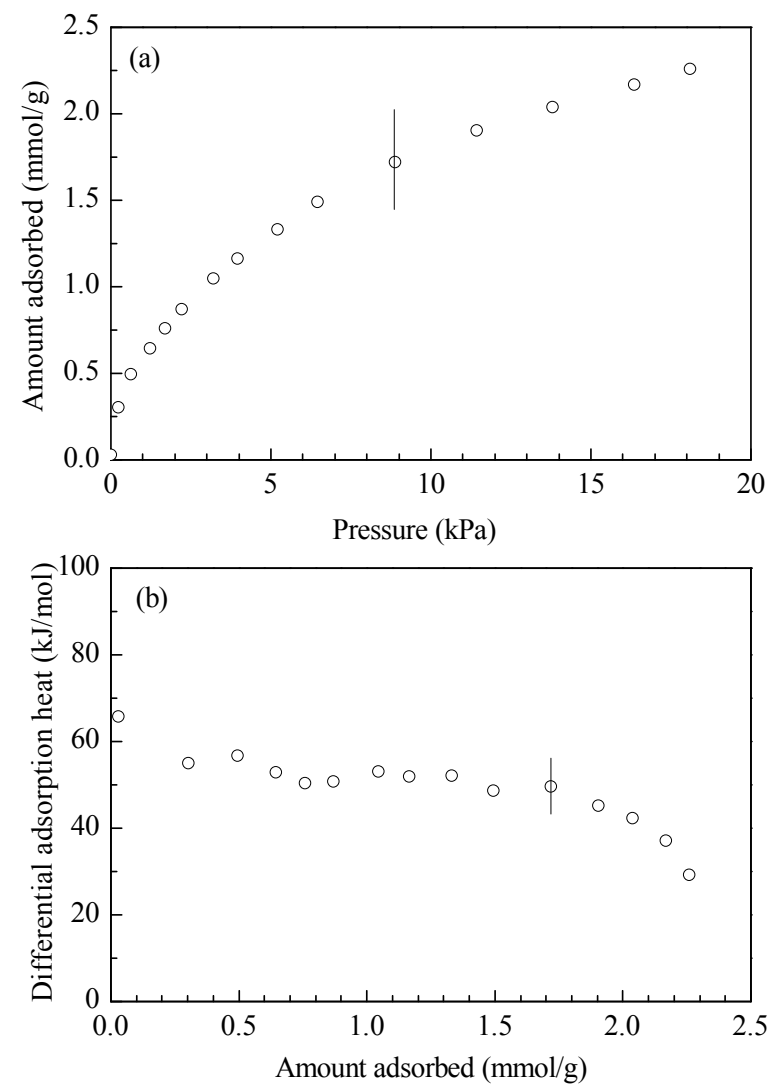

Fig. 2. (a) Total adsorption isotherm and (b) calorimetric curve of the adsorption of the methanol-DME mixture at $80^{\circ} \mathrm{C}$. Vertical lines indicate saturation of Type 1 sites where a drop occurred in the calorimetric curve. 

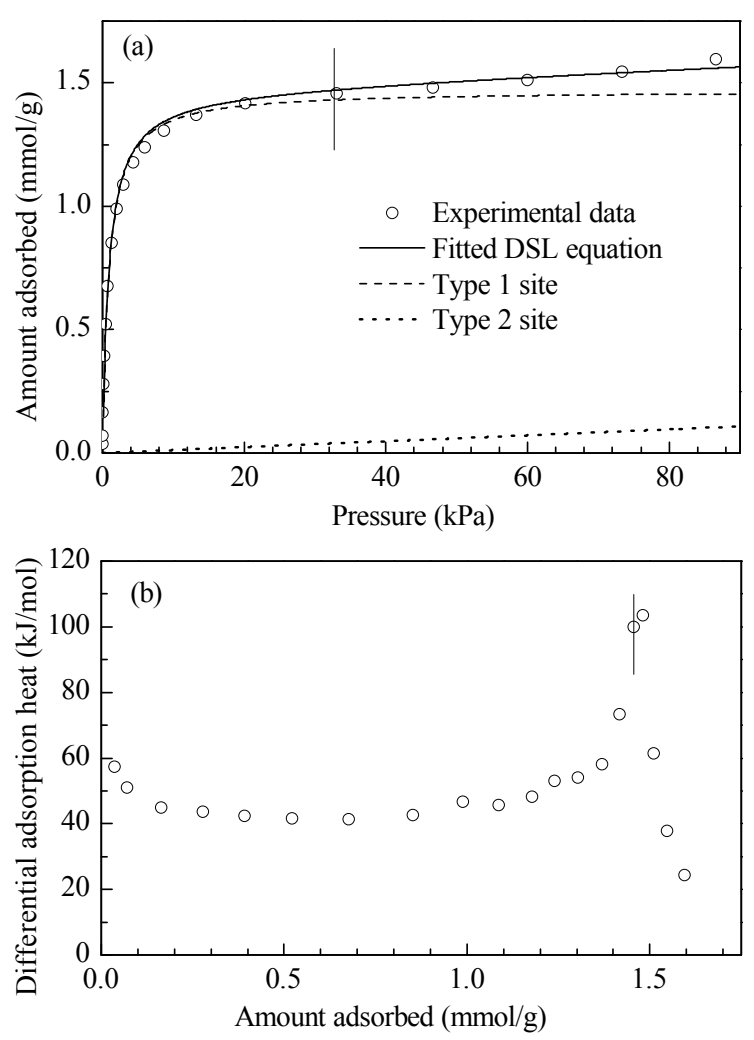

Fig. 3. (a) Adsorption isotherms and (b) calorimetric curve of DME on SAPO- 34 at $25^{\circ} \mathrm{C}$. Vertical lines indicate saturation of Type 1 sites indicated by a sharp drop in adsorption heat.

to quite high pressures was probably due to the entropy factor in the thermodynamics. However, it was obvious that the surface was enriched in adsorbed methanol and the overall adsorption stoichiometry was closer to two than to one.

\subsection{DME-ethene binary mixture}

The binary component experiment with DME and ethene was conducted at $25{ }^{\circ} \mathrm{C}$ because ethene showed some reaction at higher temperatures. Their pure component measurements are presented in Figs. 3 and 4. For DME, the calorimetric curve showed that the saturation capacity on Type 1 sites, which was shown by the sharp fall in the calorimetric curve, was 1.47 $\mathrm{mmol} / \mathrm{g}$. After the saturation of the acid sites, further adsorption on the weaker Type 2 site, which was possibly physisorption on the non-acidic surface of the zeolite, was also observed. On the other hand, a sharp drop was not observed in the calorimetric curve of ethene, but instead the heat of adsorption showed a gradual decrease. This was due to that there was significant adsorption on Type 2 sites already before Type 1 sites were saturated. In this case, it was difficult to obtain the saturation amount of Type 1 sites from the calorimetric curve. Therefore, we assumed that for ethene, the saturation amount on Type 1 sites was $1.0 \mathrm{mmol} / \mathrm{g}$, which was the value for the acid site density calculated from SEM-EDS from the measured $\mathrm{Si} / \mathrm{Al}$ ratio, which assumed that there were no Si islands because of the small amount of $\mathrm{Si}$, and $\mathrm{NH}_{3}$-TPD data [9]. Using
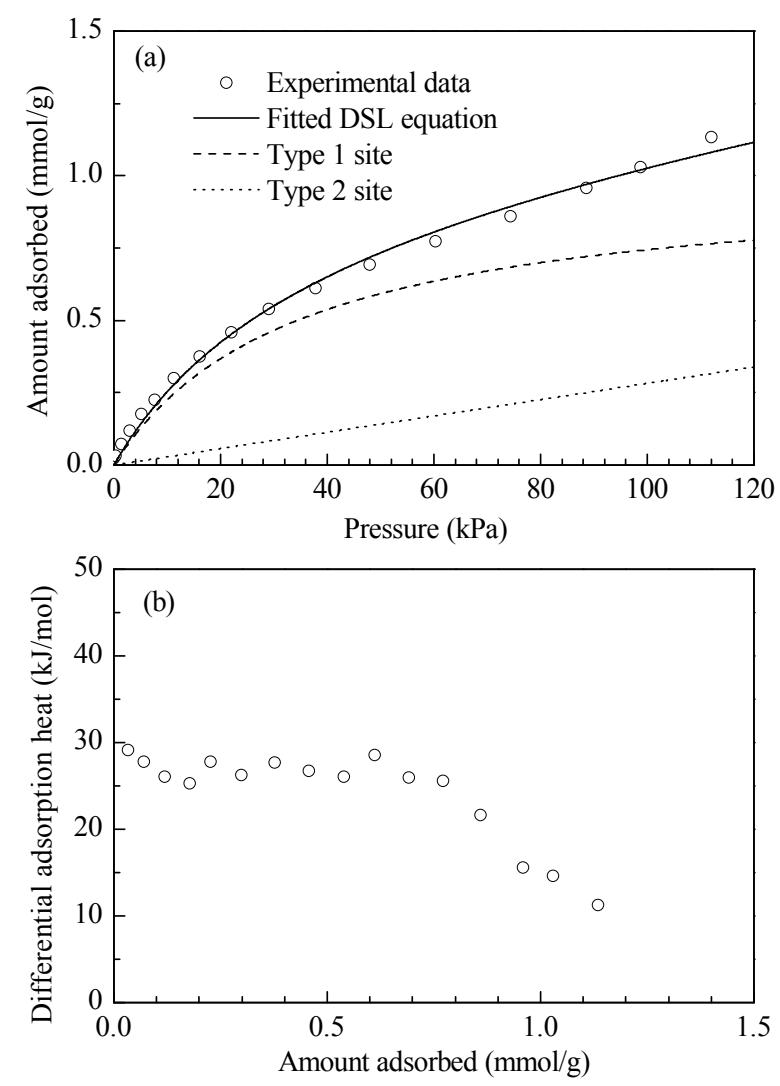

Fig. 4. (a) Adsorption isotherms and (b) calorimetric curve of ethene on SAPO- 34 at $25^{\circ} \mathrm{C}$.

this value, the DSL equation was used to fit the data points. The fitted isotherms are presented in Figs. 3(a) and 4(a). The DSL parameters are given in Table 1. An interesting feature of this system is that on Type 1 sites, DME had a larger saturation adsorption capacity and larger adsorption equilibrium constant, while on Type 2 sites, ethene had the larger Henry's constant, which was shown by the slope of the isotherms in the corresponding pressure regions. This feature would indicate that the two adsorbates have different interactions with the two different sites. Unfortunately, we were unable to get the saturation adsorption capacity on Type 2 sites because this would require adsorption at higher pressure than our apparatus can reach, and the maximum measurement pressure was quite low with methanol because of its low vapor pressure.

Figure 5 shows the measured adsorption isotherm and calorimetric curve due to adsorption from the DME-ethene gas mixture. Figure 6 shows the measured individual concentrations of DME and ethene due to adsorption from the gas mixture along with the calculated results from Langmuir theory and IAST using the pure component DSL parameters. The same trends as with the methanol-DME binary mixture were observed: (1) the two theories were in agreement and in agreement with the experimental amounts of adsorbed DME and ethene at low pressures, (2) deviations from the experimental data points in the calculations using Langmuir theory became larger in the higher pressure region while the IAST calculations agreed with experimental data, and (3) these deviations were 

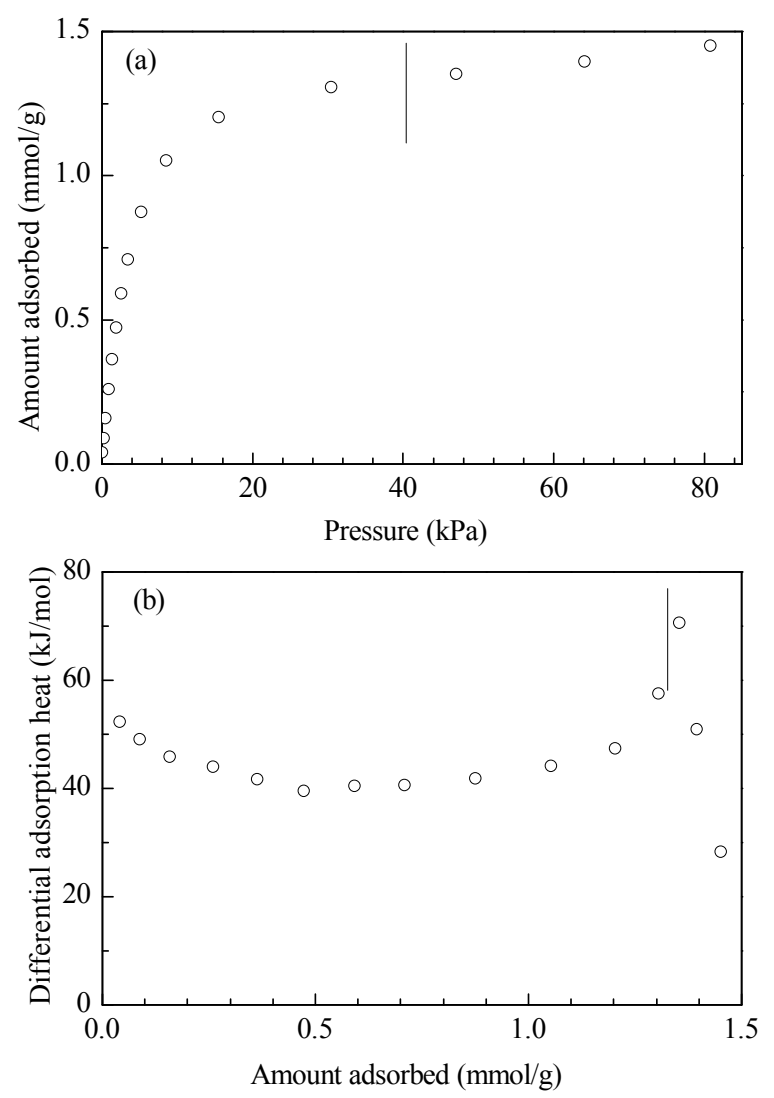

Fig. 5. DME-ethene gas mixture (a) adsorption isotherm and (b) calorimetric curve at $25^{\circ} \mathrm{C}$. Vertical lines indicate saturation of Type 1 sites shown by a heat drop in the calorimetric curve.

due to that the adsorbate with the smaller saturation capacity was no longer being adsorbed, and then with further increase in pressure, some adsorbed amount actually desorbed. However, the third trend here also had a difference to that in Fig. 1 in that after the amount of adsorbed ethene decreased up to 39 $\mathrm{kPa}$ where the Type 1 sites were saturated, it then started increasing above $39 \mathrm{kPa}$ total pressure. Since it was observed in the pure component isotherm measurements that ethene adsorbed on Type 2 site more strongly than DME, this subsequent increasing trend was probably due to preferential adsorption of ethene on Type 2 sites. In any event, similar to the methanol-DME binary mixture experiment, IAST correctly captured the whole curve of the amount of adsorbed ethene versus gas mixture pressure, while the Langmuir equation did not.

\section{Conclusions}

Adsorption measurements with mixtures of adsorbates that have different adsorption capacities showed that the IAST gave accurate calculations over the whole range of coverages in competitive multicomponent adsorption on a SAPO-34 zeolite, while the Langmuir equation for competitive adsorption was correct only in the calculations of the low coverage regions. For binary mixtures of methanol-DME and DME-ethene, the deviations between the Langmuir calculation and experiment began to be significant when the total coverage exceeded one-third.
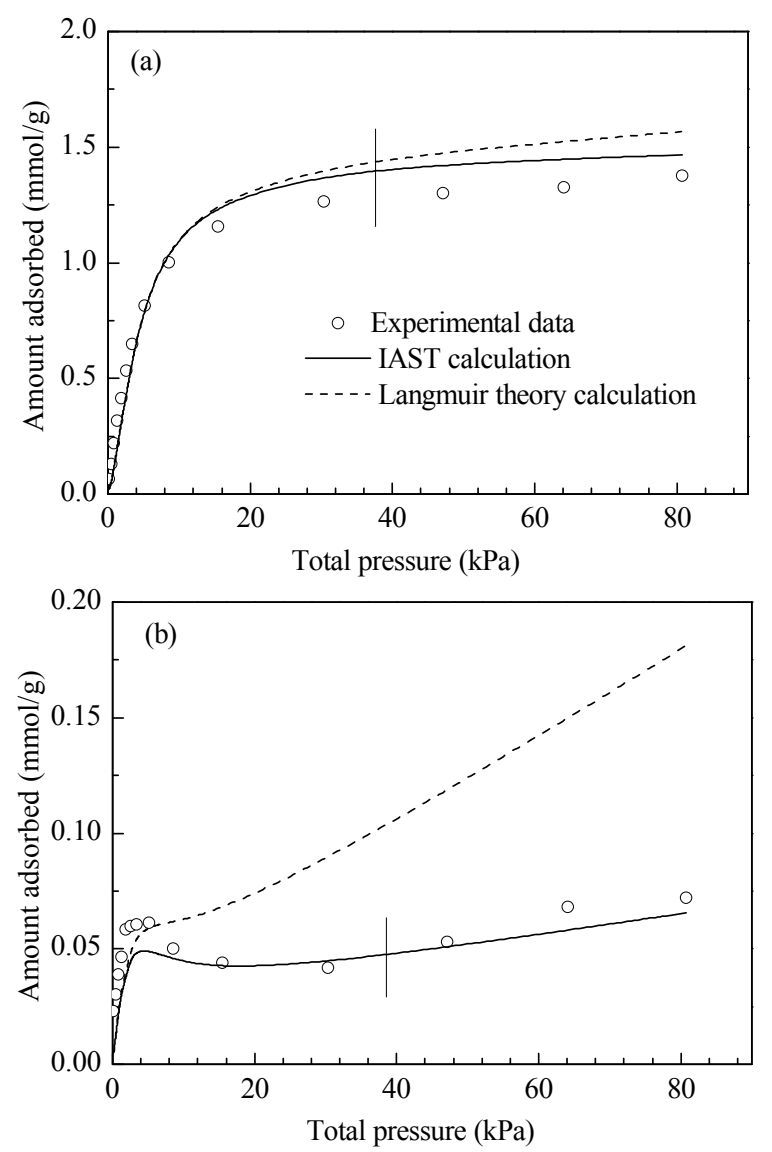

Fig. 6. Surface concentration of (a) DME and (b) ethene due to adsorption of the binary gas mixture. Vertical lines indicate the saturation amount of Type 1 sites where a sharp drop in adsorption heat occurred.

\section{References}

[1] Do D D. Adsorption Analysis: Equilibria and Kinetics. London: Imperial College Press, 1998

[2] Yang R T. Adsorbents: Fundamentals and Applications. New Jersey: John Wiley \& Sons Inc, 2003

[3] Krishna R, Baur R. Chem Eng Sci, 2005, 60: 1155

[4] Ruthven D M. Mol Sieves, 2008, 7: 1

[5] Lok B M, Messina C A, Patton R L, Gajek R T, Cannan T R, Flanigen E M. US Patent 4440871.1984

[6] Tan J, Liu Z M, Bao X H, Liu X C, Han X W, He C Q, Zhai R S. Microporous Mesoporous Mater, 2002, 53: 97

[7] Li Y X, Zhang M Y, Wang D Z, Wei F, Wang Y. J Catal, 2014, 311: 281

[8] Li W J, Wang Y, Wang D Z, Wei F. Chin J Catal (李文俊, 王圭, 王德 峥, 魏飞. 催化学报), 2006, 27: 200

[9] Kobayashi Y, Li Y X, Wang Y, Wang D Z. Chin J Catal (Kobayashi Y, 李玉新, 王圭, 王德峥. 催化学报), 2013, 34: 2192

[10] Handy B E, Sharma S B, Spiewak B E, Dumesic J A. Meas Sci Technol, 1993, 4: 1350

[11] Mathias P M, Kumar R, Moyer J D Jr, Schork J M, Srinivasan S R, Auvil S R, Talu O. Ind Eng Chem Res, 1996, 35: 2477

[12] Krishna R, Vlugt T J H, Smit B. Chem Eng Sci, 1999, 54: 1751

[13] Barcia P S, Nicolau M P M, Gallegos J M, Chen B L, Rodrigues A E, Silva J A C. Microporous Mesoporous Mater, 2012, 155: 220

[14] Myers A L, Prausnitz J M. AlChE J, 1965, 11: 121

[15] Krishna R, van Baten J M. Sep Purif Technol, 2008, 61: 414 


\title{
Graphical Abstract
}

Chin. J. Catal., 2014, 35: 430-436 doi: 10.1016/S1872-2067(14)60007-3

Species surface concentrations on a SAPO-34 catalyst exposed to a gas mixture

Yasukazu Kobayashi, Yuxin Li, Yao Wang, Dezheng Wang*

Tsinghua University

Methanol has a larger adsorption capacity than dimethyl ether (DME) on SAPO-34, which caused DME coverage to decrease with increasing pressure of a gas mixture. Ideal adsorbed solution theory calculations showed this but the Langmuir isotherm for competitive adsorption did not.

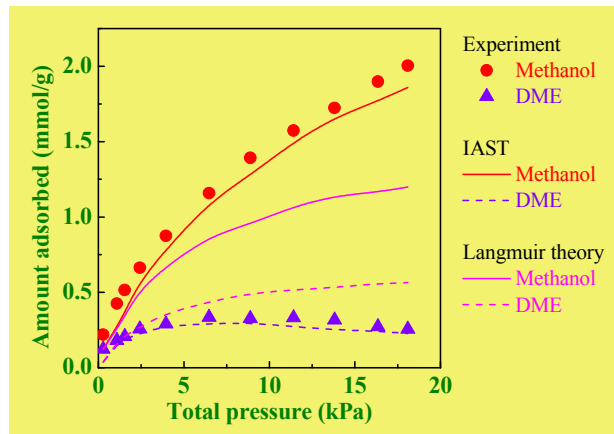

\section{混合气体中SAPO-34上单个物种的表面浓度}

\author{
Yasukazu Kobayashi, 李玉新, 王 圭, 王德峥* \\ 清华大学化学工程系, 北京 100084
}

摘要: 运用Langmuir等温线方程和理想吸附溶液理论(IAST)两种方法计算了SAPO-34在混合气体中的单个物种表面浓度, 并对比 了计算值与实验值的吻合程度. 考察了两个二元混合体系, 分别为 $80{ }^{\circ} \mathrm{C}$ 的甲醇和二甲醚以及 $25^{\circ} \mathrm{C}$ 的二甲醚和乙烯混合气, 发现 IAST计算值在实验压力范围内均与实验结果吻合; 但是Langmuir理论计算值仅在酸性位覆盖率低于 $1 / 3$ 时与实验值吻合较好, 随 着压力增加严重偏离实验值, 而且Langmuir理论不能描述随压力增加低饱和吸附量物种覆盖率降低的现象. 因此, 针对包含不同 饱和吸附量组分的混合气, Langmuir理论仅适用于描述表面浓度低时的反应动力学, 当表面浓度高时应该采用IAST方法.

关键词：理想吸附溶液理论; 吸附等温线; 混合气体吸附; SAPO-34

收稿日期: 2013-10-26. 接受日期: 2013-12-23. 出版日期: 2014-03-20.

*通讯联系人. 电话: (010)62794467; 传真: (010)62772051; 电子信箱: wangdezheng@tsinghua.edu.cn

基金来源: 国家自然科学基金(21173125).

本文的英文电子版由Elsevier出版社在ScienceDirect上出版(http://www.sciencedirect.com/science/journal/18722067). 